\title{
O papel das cooperativas de crédito na territorialização das políticas de apoio à agricultura familiar - o caso do movimento cooperativo no estado de Santa Catarina-SC
}

Ademir Antonio Cazella* Marielle Berriet-Solliec ${ }^{* *}$

\section{Resumo}

As cooperativas de crédito do Brasil aparecem hoje como vetores potenciais do desenvolvimento da agricultura familiar e como alternativas operacionais ao sistema nacional de crédito rural. Com base nesta constatação, este artigo apresenta uma análise do papel efetivo das cooperativas de crédito a partir de pesquisas efetuadas no estado de Santa Catarina, historicamente reconhecido como uma das zonas geográficas onde os sistemas cooperativos conheceram certo dinamismo e onde o número de agricultores familiares é relativamente importante em relação às outras regiões brasileiras. Esta análise cruza o olhar de dois economistas, um especializado nos mecanismos de financiamento da agricultura familiar e o outro nos processos de territorialização das políticas agrícolas e de desenvolvimento rural. $\mathrm{O}$ artigo analisa em que medida as cooperativas de crédito, de acordo com o seu modo de organização, contribuem para a melhoria da eficácia e do acesso ao crédito dos agricultores familiares, graças à adoção de processos de intervenção territorializados.

Palavras-chave: Desenvolvimento territorial; Políticas públicas; Crédito rural.

** Universidade Federal de Santa Catarina (acazella@cca.ufsc.br).

** Etablissement National d'Enseignement Supérieur Agronomique de Dijon (berriet@dijon.inra.fr).

Geosul, Florianópolis, v. 25, n. 50, p 83-106, jul./dez. 2010 
CAZELLA, A.A. \& BERRIET-SOLLIEC, M. O papel das cooperativas ...

The role of credit cooperatives in the territorialization of policies to support family agriculture - the case of the cooperative movement in the state of Santa Catarina-SC

\begin{abstract}
Credit cooperatives in Brazil are potential vectors for the development of family farming and operational alternatives to the national rural credit system. Based on this finding, this text presents an analysis of the effective role of credit cooperatives based on studies conducted in Santa Catarina State, historically recognized as having dynamic cooperative systems and where the number of family farmers is relatively important in relation to other Brazilian regions. This analysis considers the perspective of two economists, one specialized in financing mechanisms for family farming and the other in the processes of territorialization of agricultural policies and rural development. The article analyzes the degree to which the credit cooperatives, according to their mode of organizations, contribute to improving access to credit and its effective use by family farmers, thanks to the adoption of territorialized intervention processes.
\end{abstract}

Key words: Territorial development; Public policies; Rural credit.

\title{
Introdução ${ }^{1}$
}

Embora as cooperativas de crédito existam no Brasil desde 1920, foi apenas depois do regime militar, a partir dos anos 1980,

${ }^{1}$ Este artigo foi apresentado no colóquio Les coooperatives agricoles: mutations et perspectives, organizado em Paris pela Société Française d'Economie Rurale, nos dias 28 e 29/02/2008, e no V Encontro de Pesquisadores Latino-Americanos de Cooperativismo, realizado em Ribeirão Preto no período de 06 a 08/08/2008. Trata-se de um estudo ligado ao programa de cooperação internacional Capes/Brafagri e ao projeto Sistemas Agrários e Desenvolvimento Territorial. 
CAZELLA, A.A. \& BERRIET-SOLLIEC, M. O papel das cooperativas ...

que elas retomaram suas atividades e aparecem, dessa vez, como vetores potenciais do desenvolvimento da agricultura familiar e como alternativas para o sistema de gestão de políticas públicas de crédito rural. Em particular, as cooperativas de crédito rural podem desempenhar as funções de facilitar a implementação do Programa Nacional de Fortalecimento da Agricultura Familiar (Pronaf), que existe no Brasil desde 1996, e de melhorar a sua eficácia (CAZELLA, 2002). No contexto atual, o Banco do Brasil é o principal interlocutor para o acesso aos empréstimos agrícolas atribuídos no âmbito do Pronaf, sendo que cerca de 2 milhões dos 4,1 milhões de agricultores familiares acederam a este programa de crédito. Embora esse total seja significativo face à fragilidade do sistema financeiro e da organização sociopolítica dos agricultores em muitas zonas rurais, isso representa menos de $50 \%$ da agricultura familiar brasileira (CAZELLA, 2005).

Os resultados apresentados neste trabalho baseiam-se em entrevistas realizadas junto a duas cooperativas de crédito associadas a sistemas de gestão diferentes - situadas em Santa Catarina. Esse estado é historicamente reconhecido como uma das zonas geográficas onde os sistemas cooperativos conheceram um certo dinamismo e onde o número de agricultores familiares é relativamente importante em relação às outras regiões brasileiras (ASSANKPON, 2007). A questão central deste trabalho se desdobra em dois aspectos: como as cooperativas de crédito contribuem para melhorar a eficácia e o acesso ao crédito dos agricultores familiares, de acordo com o seu modo de organização e tipo de sistema de gestão aos quais estão afiliadas? Em que suas ações contribuem para uma maior territorialização das políticas públicas destinadas a agricultores familiares? A hipótese testada aqui é que as cooperativas afiliadas ao sistema de economia solidária, diferente do sistema convencional, estão a priori, pelas suas relações mais estreitas com os beneficiários e os seus conhecimentos mais aprofundados acerca dos desafios dos seus territórios, melhor habilitadas a gerir o Pronaf e a criar formas adequadas de créditos. 
CAZELLA, A.A. \& BERRIET-SOLLIEC, M. O papel das cooperativas ...

De antemão, torna-se necessário precisar o que entendemos por "territorialização". Na literatura sobre a análise da intervenção pública, a territorialização corresponde a vários processos e dimensões (BERRIET-SOLLIEC et al., 2008): uma adaptação aos diferentes contextos locais, independentemente da escala de intervenção político-administrativa (TROUVÉ, 2007), uma tendência à definição e à orientação dos problemas econômicos pelas instituições públicas infra-nacionais encarregadas (DOUILLET, 2003) e, por último um reforço de espaços de gestão, de territórios construídos, cuja delimitação se estabelece por tipo de problema a tratar (DURAN e THOENIG, 1996). Nos limitamos aqui à conjugação das duas primeiras dimensões. Por conseguinte, procuramos, neste artigo, analisar como a intervenção das duas cooperativas de crédito se traduz na forma de apoio institucional, expresso em escala local, permitindo que sejam levadas em conta as necessidades ou desafios dos agricultores familiares.

Inicialmente, como o desenvolvimento das cooperativas de crédito em questão está estreitamente ligado à elaboração da política brasileira de apoio às unidades agrícolas familiares, parece-nos essencial retraçar o histórico dessa política. Em particular pretendemos evidenciar as principais razões da emergência progressiva de movimentos ligados ao cooperativismo de crédito no Brasil, sobretudo nos estados do Sul.

\section{Perspectiva histórica da política de apoio às propriedades familiares}

\section{Do Sistema Nacional de Crédito Rural (SNCR) ao nascimento do Programa Nacional de Fortalecimento da Agricultura Familiar}

Apesar da existência de iniciativas públicas de crédito agrícola no Brasil desde os anos 1930 (sempre orientados para as grandes propriedades agrícolas), apenas a partir de meados dos anos 1960 é que o governo reconhece de forma contundente a importância do crédito destinado à agricultura. A decisão tomada a partir de 1967 sobre o uso do crédito para apoiar o 
CAZELLA, A.A. \& BERRIET-SOLLIEC, M. O papel das cooperativas ...

desenvolvimento agrícola foi operacionalizada pela implantação do Sistema Nacional de Crédito Rural (SNCR) ${ }^{2}$. Assim, os recursos geridos pelo SNCR aumentaram consideravelmente até o início anos 1980, quando atingiram 30 bilhões de dólares anuais de crédito rural (BURIGO, 2007).

O SNCR desde a sua criação se orientou para a promoção de uma agricultura intensiva, estreitamente ligada ao setor agroindustrial (adubos químicos, fitossanitários, máquinas agrícolas). Essa política teve importantes efeitos de concentração econômica e geográfica. De fato, privilegiou os produtos de exportação voltados para transformação agroindustrial, as regiões Sul e Sudeste e os produtores de médio e grande porte (SAYAD, 1984; Delgado, 1985).

No início da década de 1980, no quadro de um processo de abertura política, redemocratização do país e aumento das pressões populares, mas também de crescimento da inflação e da dívida externa, o SNCR é colocado em questionamento. A partir desta época, os movimentos sindicais e sociais denunciam o fato do crédito rural ser quase exclusivamente reservado às empresas patronais, nas quais predomina o trabalho assalariado e uma orientação produtiva voltada para o mercado externo, enquanto que os agricultores familiares enfrentam grandes dificuldades para ter acesso aos financiamentos públicos. É nesse período que as desigualdades entre os dois tipos de explorações (patronais $\mathrm{X}$ familiares) começam a se tornar mais conhecidas e estudadas.

Dos anos 1980 até a metade dos anos 1990, a política de crédito agrícola continuou orientada para os agricultores mais eficientes do ponto de vista produtivo, em particular para aqueles que produzem para exportação (cana-de-açúcar, laranja, soja...). Paralelo a isso, observa-se o crescimento das pressões políticas dos movimentos sociais e sindicais, representando os interesses dos

${ }^{2}$ Cabe ressaltar que o SNCR se consolidou ao mesmo tempo que entrava em vigor leis limitando a ação das cooperativas de crédito (BURIGO, 2007). Retomamos esse assunto na segunda parte deste artigo. 
CAZELLA, A.A. \& BERRIET-SOLLIEC, M. O papel das cooperativas ...

agricultores familiares. Esses últimos reivindicam políticas públicas específicas para os agricultores que utilizam de forma predominante a mão-de-obra familiar. Além disso, em reforço a essas reivindicações, vários estudos colocam em destaque a importância da agricultura familiar para a produção de alimentos destinados ao mercado interno, a criação de empregos e a promoção do desenvolvimento local.

\section{A instauração de uma política de apoio à agricultura familiar}

É, então, nos anos 1980 e 1990, a partir da pressão da sociedade civil, associada a novas orientações de instituições internacionais (Banco Mundial), que o governo foi conduzido a modificar sua política de apoio em favor dos agricultores familiares e a formular programas de crédito subvencionados para esse tipo específico de agricultores. Ainda em 1993, o Programa de Valorização da Pequena Produção Rural (Provap) precursor do Pronaf, teve início (BURIGO, 2007). Contudo, foi necessário esperar o ano de 1995 e as revisões do Provap, para se ter a criação do Pronaf. Esse programa visa apoiar a agricultura familiar por meio de auxílio técnico e financeiro. Seus principais objetivos são de contribuir para a criação de empregos e incremento de renda nas zonas rurais, melhorando a qualidade de vida dos agricultores familiares.

Do ponto de vista operacional, o Pronaf tem quatro linhas de ação: i) financiamento da produção por meio de crédito de custeio e de investimento; ii) crédito para formação e profissionalização dos agricultores familiares; iii) financiamento da pesquisa e da extensão rural voltado para a agricultura familiar; iv) financiamento de infra-estruturas e serviços municipais, que recentemente se tornou um crédito de desenvolvimento territorial (financiamento de projetos intermunicipais).

A primeira modalidade deste programa é a mais importante em volume de recurso e número de agricultores beneficiados. Apesar dos seus limites, todas as avaliações desse programa 
CAZELLA, A.A. \& BERRIET-SOLLIEC, M. O papel das cooperativas ...

convergem para destacar sua importância, representando "uma alternativa concreta para diversos segmentos da agricultura familiar brasileira" (MATTEI, 2005). Os últimos dados disponíveis sugerem que praticamente a metade dos agricultores familiares (dois milhões) é atendida por esta política. Se for considerado o fato de uma parcela de agricultores familiares não ser contemplado pelo Pronaf por possuir rendas superiores ao teto estabelecido pelas normas do Programa, o índice do público alvo atendido é relevante.

Três elementos referentes à trajetória do Pronaf merecem ser ressaltados. O primeiro é que esse programa concretiza a emergência de uma verdadeira política de apoio ao desenvolvimento da agricultura familiar no Brasil e que procura dar conta da diversidade social desse segmento ${ }^{3}$. O segundo é que, em razão da forte participação da sociedade civil e dos movimentos sociais rurais, ele é periodicamente revisto, com a adoção de novas regras no que diz respeito às taxas de juro, prazos, valores máximos dos créditos, mas também através da introdução de novas linhas de financiamento destinadas às atividades e a um público específico: jovens rurais, mulheres agricultoras, habitantes de zonas semi-áridas, agroecologia, pequenas agroindústrias familiares (BURIGO, 2007). Finalmente, o terceiro elemento a ressaltar refere-se ao fato de que o segundo período do programa é

${ }^{3}$ Inicialmente, os beneficiado foram sub-divididos em cinco grupos: os beneficiados pela política da reforma agrária (grupo A) e, segundo o nível de renda monetária, o Grupo B (quase sem renda), Grupo C (baixa renda) e Grupos D e E (renda média e alta). Uma parcela de agricultores familiares não é beneficiária do Pronaf por apresentar rendas brutas anuais superiores a $\mathrm{R} \$ 110$ mil reais e/ou áreas de terras acima de quatro módulos fiscais . A partir do ano-safra 2008-09, esse sistema de classificação foi reestruturado com a extinção dos Grupos C, $\mathrm{D}$ e $\mathrm{E}$ e a adoção de taxas de juros progressivas segundo o valor do financiamento. 
CAZELLA, A.A. \& BERRIET-SOLLIEC, M. O papel das cooperativas ...

marcado por uma melhor difusão dos empréstimos em todo Brasil ${ }^{4}$, mesmo que a região Sul continue sendo a mais importante em sua aplicação. É também nessa região que o movimento cooperativo emergiu, conforme veremos na segunda parte deste artigo.

\section{Emergência progressiva de iniciativas de crédito rural territoriais: o incremento das cooperativas de crédito}

O breve histórico apresentado na primeira parte nos permitiu relembrar os desafios da política brasileira de apoio à agricultura familiar. Neste tópico procuramos analisar em que o reforço da intervenção das cooperativas de crédito contribuiu para uma gestão mais territorializada dos créditos do Pronaf, uma maior eficácia nas atribuições dos empréstimos face ao número de contratos assinados e uma maior diversidade dos tipos de agricultores assistidos? Como a emergência das cooperativas de crédito no Brasil permitiu responder os desafios dessa territorialização da política de apoio à agricultura familiar? E quais são as modalidades de funcionamento? Para responder essas questões partimos da apresentação da organização atual das cooperativas de crédito, em seguida retomamos o histórico dessa modalidade de cooperativas para, então, tratar das condições de emergência do cooperativismo de crédito no Brasil.

\section{Panorama das estruturas de crédito no Brasil}

A originalidade na organização das cooperativas de crédito no Brasil reside na inexistência de uma entidade única que reagrupa todas as cooperativas. Essas últimas estão estruturadas em quatro sistemas principais, a saber: Sicoob, Sicredi e Unicredi e a Associação Nacional do Cooperativismo de Crédito de Economia Familiar e Solidária (Ancosol). Os três primeiros estão ligados ao

\footnotetext{
${ }^{4} \mathrm{O}$ Sul deteve $60,5 \%$ dos contratos em 1999 e 38,5\% em 2004, enquanto que a região Nordeste representou, em 2004, 36\% dos contratos contra 22\% em 1999 (MATTEI, 2005).
} 
CAZELLA, A.A. \& BERRIET-SOLLIEC, M. O papel das cooperativas ...

sistema convencional de cooperativas agropecuárias, enquanto que a Ancosol representa o sistema alternativo ou solidário. Entre esses quatro sistemas, o Unicredi é o único que não trabalha com o crédito agrícola, já que os profissionais da saúde são seu público.

Mais precisamente, a Ancosol não é um sistema, mas uma rede de pequenos sistemas. Essa rede teve início em junho de 2004 e reagrupa sistemas que se distinguem pela sua organização menos verticalizada, contrastando com os sistemas de cooperativas de crédito convencionais (Sicoob, Unicredi, Sicredi). É necessário ressaltar que dentro dessa Associação se encontra a Cooperativa Central de Crédito Rural com Interação Solidária (Cresol), que é o resultado de um movimento conjunto de várias instituições (de apoio e sindical) de pequenos agricultores dos estados do Sul do país. Ela traduz as premissas da criação de um sistema cooperativo de crédito agrícola que não esteja ligado às grandes cooperativas de produtores agropecuários. No tópico seguinte analisamos as principais razões da diferenciação progressiva dessas formas de organização financeira e de crédito rural.

\section{As origens do cooperativismo de crédito rural no Brasil}

As primeiras cooperativas de crédito começaram no Sul do País nos anos 20. A partir dos anos 40, as cooperativas de crédito ganharam maior institucionalidade. $\mathrm{O}$ governo federal estimulou, num primeiro momento, o desenvolvimento das cooperativas por dois decretos sucessivos (1926 e 1932), que deram um quadro legal ao movimento cooperativo. Essas ações do Estado permitiram uma expansão das cooperativas nas décadas de 40 e 50 e a criação, em 1943, da Caixa de Crédito Cooperativo. Essa Caixa foi transformada, em 1951, no Banco Nacional de Crédito Cooperativo (BNCC), com uma forte participação do Estado na sua gestão. Trata-se, de um banco público de apoio às cooperativas agrícolas e não de um banco comercial. O BNCC foi extinto no início dos anos 1990 no bojo das políticas de privatização e de redução das intervenções do Estado na economia. 
CAZELLA, A.A. \& BERRIET-SOLLIEC, M. O papel das cooperativas ...

Essa primeira fase de expansão foi seguida, a partir dos anos 1950, por um período onde a maioria das cooperativas de crédito se encontrava em grandes dificuldades decorrentes de restrições financeiras impostas pelo Sistema Financeiro Nacional (SFN). Sua situação se agrava nos anos $60 \mathrm{com}$ a instauração do governo militar, que impede a criação de novas cooperativas de crédito e institui fortes restrições ao funcionamento daquelas já existentes. Ainda, nos anos 70, o número de cooperativas de crédito, notadamente de cooperativas de crédito agrícola, diminui de forma significativa e o financiamento da agricultura é inteiramente confiado aos órgãos federais do Estado, mais especificamente ao SNCR e aos bancos públicos. Por conseguinte, a retomada do movimento cooperativo de crédito agrícola se faz graças às iniciativas das cooperativas agropecuárias convencionais a partir dos anos 1980. Com a redemocratização do país, as cooperativas de crédito reencontraram um ambiente propício para a sua reestruturação. Embora o início desse processo tenha se dado por iniciativa das estruturas convencionais já existentes, organizações alternativas começaram a ser pensadas no início dos anos 1990.

\section{A emergência de novas estruturas de cooperativas de crédito rural}

Em 1980, face ao enfraquecimento das políticas de crédito agrícola via SNCR, a Organização das Cooperativas do Brasil (OCB) se engaja na reorganização das cooperativas de crédito. De 1980 a 2000, as cooperativas de crédito tiveram um crescimento exponencial, particularmente nos três estados do Sul. No início dos anos 1990, uma rede de ONG do sul incorporou esse tema nas suas agendas de trabalho. No estado de Santa Catarina, o desenvolvimento desse tipo de cooperativas se explica, tanto pela eficácia do sistema de cooperativas de crédito do tipo Sicoob, quanto pela criação de cooperativas de crédito alternativo do tipo Cresol. 
CAZELLA, A.A. \& BERRIET-SOLLIEC, M. O papel das cooperativas ...

Nesse estado, a partir de 1985 , se tem uma retomada do movimento de cooperativismo de crédito. Sete cooperativas de crédito e duas cooperativas agrícolas se reúnem para formar a então Cooperativa Central de Crédito de Santa Catarina (Cocecrer/SC). Essa iniciativa regional foi progressivamente integrada no quadro nacional, estruturado para acompanhar o desenvolvimento cooperativo. Em 1995, um passo determinante é dado pela OCB, com a autorização, por força de lei, da criação de bancos cooperativistas (BURIGO, 2007). Essa abertura conduz o sistema Sicoob, criado a nível nacional em 1997 em substituição às Cocecrer, a se dotar desde 2000 de seu próprio banco - Bancoob. O Sicoob/SC detém na atualidade $7 \%$ das ações desse banco, figurando entre os quatro maiores acionistas.

Para compreender a organização das cooperativas de crédito do Brasil é essencial explicar a ligação que existe entre a maioria das cooperativas de crédito do Sistema Sicoob e as cooperativas agropecuárias de produtores. De fato, a antiga Cocecrer e o atual sistema Sicoob nasceram a partir de iniciativas políticas dos dirigentes das cooperativas agropecuárias convencionais. É freqüente que sejam os mesmos dirigentes a ocupar os postos de direção nas duas modalidades de cooperativas. O movimento cooperativista nascido no período de modernização agrícola dos anos 1960-70 se caracteriza do ponto de vista político pelo seu caráter conservador. Esses sistemas cooperativos têm uma organização nacional, estando presente em praticamente todos os estados federados, e apresentam uma grande capacidade de influenciar a evolução das políticas públicas.

A exemplo do Bancoob, que é uma das maiores estruturas de cooperativas de crédito do Brasil ${ }^{5}$, o Sicoob possui uma presença notória no estado de Santa Catarina. Através de suas 45 cooperativas de crédito e 187 postos de serviços religados às cooperativas, ele abrange 59\% dos municípios do estado, ou seja

${ }^{5}$ O Bancoob está presente em 14 estados do País e conta com 789 cooperativas afiliadas, sendo $28 \%$ de cooperativas de crédito. 
CAZELLA, A.A. \& BERRIET-SOLLIEC, M. O papel das cooperativas ...

173 municípios. Em termos de representação sobre o conjunto do território de Santa Catarina, somente o Banco do Brasil e o Banco do Estado de Santa Catarina (BESC) estão na frente do Sicoob-SC.

O desenvolvimento das cooperativas do Sicoob traduz uma primeira forma de territorialização do sistema de crédito. Mas esta forma de organização se revela ainda insuficiente quanto à consideração das necessidades dos pequenos produtores. É por isso que, a partir de 1990, face à constatação de que as cooperativas de crédito do sistema convencional não contemplam a maioria dos pequenos agricultores, a sociedade civil (ONG e movimentos populares) se mobiliza para encontrar soluções alternativas, a fim de facilitar o acesso ao crédito dos agricultores familiares que não integram o cooperativismo tradicional.

Nesse contexto, o Centro de Estudos e Promoção da Agricultura de Grupo (Cepagro ${ }^{6}$ ) foi encarregado de coordenar as discussões e de elaborar propostas nessa direção, com estreita colaboração de pesquisadores da Universidade Federal de Santa Catarina. Uma comissão de crédito é então encarregada de elaborar um estudo sobre o crédito rural. Este estudo constata que a forte ligação existente entre as cooperativas de produtores rurais e as cooperativas de crédito provoca a exclusão dos agricultores não associados ao primeiro tipo de cooperativas. Os financiamentos acordados pelas cooperativas de crédito eram destinados quase que exclusivamente à compra de insumos agrícolas vendidos pela cooperativa de produtores. A comissão propôs, então, a organização de cooperativas de crédito independentes das cooperativas de produtores. Isso viria a representar um tema de

\footnotetext{
${ }^{6}$ Esta ONG foi criada no fim dos anos 1980 com o objetivo de coordenar projetos de desenvolvimento rural com a participação de outras Organizações existentes no interior do estado de Santa Catarina. Localizado em Florianópolis, o Cepagro foi a primeira ONG a propor a organização de cooperativas de crédito para os pequenos agricultores excluídos pelos bancos e pelo sistema Cocecrer/Sicoob.
} 
CAZELLA, A.A. \& BERRIET-SOLLIEC, M. O papel das cooperativas ...

divergência constante entre esse movimento alternativo e os dirigentes das cooperativas convencionais (CAZELLA, 2002).

No período de 1993 a 1999, onze cooperativas de crédito foram criadas sob o impulso da rede de ONG locais, Cepagro, Universidade e atores institucionais dos municípios envolvidos (câmaras municipais de vereadores, serviço público de extensão rural, sindicatos agrícolas). Contudo, contradições e divergências políticas emergem rapidamente entre as novas cooperativas e a direção da então Cocecrer-SC. Os motivos de divergência são múltiplos: (i) a política de inclusão de um maior número de agricultores dentro do quadro social das novas cooperativas; (ii) o baixo valor das cotas sociais e por conseqüência do capital social subscrito; (iii) a independência das novas cooperativas em relação às cooperativas de produtores; (iv) a preferência das cooperativas convencionais em aplicar no mercado financeiro os recursos captados ao invés de emprestar aos associados; (v) a política de ampliação das cooperativas já existentes por intermédio da abertura de postos de atendimento cooperativo ao invés da criação de novas cooperativas; (vi) e, não menos importante, divergências ideológicas, já que os dirigentes do movimento alternativo mantêm uma forte ligação com movimentos populares e sindicais, enquanto que o movimento das cooperativas convencionais é marcado por posições políticas conservadoras.

Essas divergências de posição levaram ao rompimento das relações entre as ONG e o sistema convencional e à constituição, em 1996, do sistema Cresol, que reúne cooperativas de crédito solidário dos três estados do sul do Brasil. Ao longo dos dez últimos anos, a Cresol teve uma evolução importante, em parte decorrente da consolidação do Pronaf.

\section{O exemplo das cooperativas de crédito rural no estado de Santa Catarina}

Nesta terceira parte, analisamos duas cooperativas de crédito rural que pertencem aos dois sistemas distintos de gestão 
CAZELLA, A.A. \& BERRIET-SOLLIEC, M. O papel das cooperativas ...

apresentados acima. É necessário enfatizar que as duas cooperativas nasceram do movimento alternativo e, dessa maneira, elas não têm relações com as cooperativas agropecuárias convencionais. A primeira é filiada ao Sistema Cresol (Cresol São Joaquim) e a segunda é ligada ao Sistema Sicoob (Credicarú de São José do Cerrito). Os dirigentes da Credicarú optaram por não aderir ao novo sistema, permanecendo no interior do Sicoob-SC. As duas estão localizadas em uma zona de Santa Catarina que não tem antecedentes na organização de cooperativas agropecuárias. A região do Planalto de Santa Catarina representa, também, uma das zonas mais pobres do estado. Mesmo que o Pronaf não contemple a totalidade dos financiamentos atribuídos pelas cooperativas, concentramos nossa reflexão sobre a implementação dos créditos desse programa, por se tratar da principal política pública de apoio às unidades agrícolas familiares.

Neste tópico mobilizamos uma grade de leitura construída em torno de quatro critérios principais: i) facilidade de acesso à informação e pertinência do dispositivo; ii) grau de interconhecimento entre os agricultores e a instituição financeira; iii) natureza do acompanhamento institucional (apoio dos municípios, das ONG, dos sindicatos...); e iv) grau de implicação das cooperativas no desenvolvimento territorial, notadamente avaliando a percentagem de crédito reaplicado na economia local.

\section{Acesso à informação e pertinência do dispositivo}

Nos dois casos, as entrevistas realizadas com beneficiários dos créditos e com dirigentes e funcionários das cooperativas permitiram identificá-las como sendo importantes gestores do Pronaf na região. Assim, nos municípios onde existe uma cooperativa de crédito ou um Posto de Atendimento Cooperativo (PAC), o número de contratos de crédito é superior quando comparado aos municípios desprovidos de uma estrutura cooperativa. Isso demonstra a importância das relações de proximidade geográfica entre a estrutura de crédito e o 
CAZELLA, A.A. \& BERRIET-SOLLIEC, M. O papel das cooperativas ...

beneficiário. Nos municípios atendidos por uma cooperativa de crédito, o número de agricultores familiares que acedem ao crédito de custeio do Pronaf é, geralmente, bem superior. Os municípios da zona de estudo que não têm bancos, nem cooperativas de crédito receberam cerca de treze vezes menos recursos do Pronaf no ano 2006.

Mas essa primeira constatação precisa ser aprofundada levando em consideração os diferentes tipos de agricultores familiares. Sobre esse ponto, as entrevistas realizadas mostram que existe uma diferença muito importante entre as duas cooperativas. A Credicarú do Sicoob fez muito mais contratos para os pequenos agricultores: 48\% dos contratos do Pronaf do ano de 2006 pertenciam à modalidade C. Já em São Joaquim, houve somente $3 \%$ de contratos do Pronaf $\mathrm{C}$ e isso apesar da existência de uma estrutura de financiamento bem mais complexa nesse município: uma agência do Banco do Brasil (instituição oficial de gestão do Pronaf), um posto cooperativo do Sicoob ligado à uma cooperativa de um município vizinho e a Cooperativa do Cresol.

Esse resultado contradiz a nossa hipótese central e pode, em parte, ser justificado pela importância econômica da principal orientação produtiva da zona. De fato, em São Joaquim, a produção intensiva de maçã é predominante, enquanto que em São José do Cerrito a agricultura praticada é mais tradicional (feijão, milho, criação bovina extensiva), com produtividades muito baixas. A priori, nessa localidade existe um número mais expressivo de agricultores familiares enquadrados no tipo C. Essa explicação, no entanto, não é suficiente existindo, possivelmente, uma contradição entre os discursos dos dirigentes e das ONG de apoio ligadas ao Sistema Cresol sobre os princípios da economia solidária e as suas práticas.

Nesse sentido, seria pertinente aprofundar a análise para verificar se no município de São Joaquim os agricultores do tipo C são pouco representativos ou se simplesmente eles não vêm sendo contemplados pelas ações da cooperativa de crédito solidário. Se esse for o caso, esse processo representa o que Cazella (2006 e 
CAZELLA, A.A. \& BERRIET-SOLLIEC, M. O papel das cooperativas ... 2007) denomina de "elitização" das ações formais de desenvolvimento. Esse tipo de elitismo encontra-se presente não só nas ações dos agentes de serviços oficiais de extensão, mas também naquelas empreendidas por organizações ditas populares.

Uma outra explicação está ligada ao dinamismo interno da cooperativa de São José do Cerrito e ao aumento da sua área de abrangência geográfica para municípios limítrofes. Até um período recente, para facilitar o acesso dos agricultores ao crédito de custeio do Pronaf, os funcionários e alguns diretores da cooperativa deslocavam-se para as comunidades rurais com o propósito de preencher os formulários. Com o tempo, essa prática foi abandonada, passando-se a priorizar as relações estreitas dos agricultores com os empregados da cooperativa. Além disso, nessa cooperativa, a divulgação de informações entre o conjunto dos associados no que diz respeito às regras e às vantagens do Pronaf figura entre suas estratégias de ação.

Além disso, a cooperativa de São José do Cerrito se tornou "o banco" local, tendo adotado uma política de gestão que busca a afiliação da maioria dos agricultores das comunidades rurais, além de comerciantes locais que praticam, em paralelo, a agricultura. As entrevistas demonstram, também, a adoção de ações concretas de territorialização das políticas públicas, contribuindo para a adaptação das linhas de crédito de custeio do Pronaf à realidade local. Assim, uma regra interna foi criada que consiste em diminuir o valor máximo dos financiamentos de custeio do Pronaf que os agricultores têm direito, visando beneficiar um maior número de associados e conceder créditos com valores ajustados à capacidade de pagamento dos empréstimos. Essas medidas poderiam ser consideradas marginais se não se mostrassem adaptadas às condições dos agricultores locais, traduzindo-se numa forma de territorialização do dispositivo.

Além disso, a Credicarú oferece pequenos financiamentos com recursos próprios para operações de crédito não agrícola (problemas de saúde, viagem, compras de utensílios domésticos, etc.) e para a aquisição de equipamentos agrícolas ou de animais. 
CAZELLA, A.A. \& BERRIET-SOLLIEC, M. O papel das cooperativas ...

Nesse domínio, a Cooperativa participa de duas feiras de bovinos que são organizadas anualmente no município de São José do Cerrito por uma associação de criadores locais, cuja maioria é associada na cooperativa. A cooperativa procura então contemplar os associados participantes das feiras com créditos do Pronaf investimento e de outras fontes de recursos públicos para financiar a compra de "animais de raça", promovendo uma melhoria na qualidade genética do rebanho. Esse conjunto de estratégias explica, em grande parte, o fato da Credicarú apresentar um maior número de associados em comparação à Cresol (SJ): respectivamente, 4042 e 636 associados, no final de 2007.

De uma maneira geral, nas duas cooperativas, as linhas de crédito do Pronaf custeio e investimento são as suas principais operações de crédito agrícola. Embora isso represente um aspecto positivo de gestão territorial dessa política pública, alguns aspectos limitantes foram observados. Atualmente, os financiamentos de custeio do Pronaf são destinados a um número limitado de produtos por região devido à criação de subdivisões segundo as zonas climáticas. Por exemplo, em Santa Catarina, a Empresa de Pesquisa Agropecuária e Extensão Rural de Santa Catarina (Epagri) define, para cada zona climática, um conjunto de culturas tidas como as mais indicadas. Com isso, os financiamentos do Pronaf não cobrem nenhuma outra cultura fora dessas indicações de produção, sob pena do agricultor não ser beneficiário da política de seguro no caso de sinistros ligados ao clima. Já o crédito do Pronaf destinado ao fomento de práticas agroecológicas, que poderia romper com essa barreira, não apresenta grande difusão na zona estudada. Isso reflete, em parte, um certo comodismo das Cooperativas ao se limitarem à difusão das linhas de crédito de menor exigência operacional.

\section{A existência de interconhecimentos e de relações personalizadas}

As entrevistas indicam que, até agora, as duas cooperativas têm relações personalizadas com os seus associados, condição sine 
CAZELLA, A.A. \& BERRIET-SOLLIEC, M. O papel das cooperativas ...

qua non para a assinatura de contratos em um contexto de subinformação dos agricultores. Recordemos que o sistema Cresol tem como princípio de gestão a atribuição de uma maior importância à participação dos agricultores nas tomadas de decisão. Já o caso da cooperativa de São José do Cerrito demonstra que, mesmo dentro do sistema Sicoob, é possível ter cooperativas que adotam uma boa gestão, em particular das políticas públicas. A questão agora consiste em avaliar se a ampliação da área de abrangência prevista pela Credicarú não representará no futuro um enfraquecimento das relações personalizadas.

De fato, as evoluções atuais e as previstas pela direção dessa cooperativa suscitam questionamentos em termos de desenvolvimento territorial e de reprodução de um modo de organização de proximidade que aposta no interconhecimento. É importante notar que existe uma diferença significativa entre os dois sistemas no que diz respeito às condições de expansão das cooperativas. Dessas escolhas estratégicas dependerá a capacidade das cooperativas em perceber e adequar as políticas públicas às necessidades locais.

Assim, o sistema Cresol tomou a decisão de que, preferencialmente, cada município deva ter sua própria cooperativa, enquanto que o sistema Sicoob incita a criação de postos cooperativos nos municípios vizinhos (uma cooperativa mãe e vários postos de atendimentos). Isso explica o fato da Credicarú ter uma ação intermunicipal expressiva (três municípios e o projeto de expansão para outros quatro nos próximos anos). Já a Cresol de São Joaquim intervém apenas nesse município. Conseqüentemente, a Credicarú tem mais de 4.000 associados e a Cresol (SJ) possui menos de 700 associados. A questão relacionada a esse tema é saber até onde pode-se aumentar a área de abrangência sem perder em eficácia e democracia interna? Esse é o dilema de fundo entre essas duas estratégias. A primeira consiste em crescer, integrar um número bem maior de agricultores, fazer parcerias com outras instituições, mas tomando o risco de afastar-se dos princípios fundadores do cooperativismo. A segunda alternativa é de 
CAZELLA, A.A. \& BERRIET-SOLLIEC, M. O papel das cooperativas ...

continuar a ser de pequena dimensão, fazer projetos com um número limitado de agricultores, mas preservando o princípio da máxima participação dos associados na gestão da cooperativa. Aqui, parece-nos pertinente ter o cuidado de não tomar como verdadeira a máxima de que "small is beautiful". A pertinência de um sistema territorial não passa inexoravelmente por estruturas de dimensões reduzidas.

\section{O apoio e o acompanhamento institucional na implementação do crédito rural}

As ações empreendidas pelas cooperativas permitiram a constituição de redes institucionais com vários atores sociais presentes nos municípios. A cooperativa, nesse caso, é vetor de reconhecimento social e de confiança local, fatores propícios ao desenvolvimento territorial. A cooperativa aparece assim como um espaço de importantes trocas institucionais entre as diferentes estruturas intermunicipais.

Esse processo de territorialização está particularmente presente nas ações da cooperativa Credicarú. De fato, o seu funcionamento se caracteriza pela participação, através da figura do seu presidente, na implementação de políticas ditas de desenvolvimento territorial fomentadas, sobretudo, pelos Ministérios do Desenvolvimento Agrário e do Desenvolvimento Social. Assim, a cooperativa participa dos principais fóruns regionais de discussão e de gestão de políticas públicas, a exemplo daquelas ligadas ao Programa Fome Zero, que procura auxiliar as famílias mais pobres de cada região. Além disso, ela tem uma boa relação com gestores da administração municipal e participa da maioria das ações promovidas pela câmara de vereadores. Além disso, mesmo que essa cooperativa não tenha seguido a orientação política da principal ONG da região - Centro Vianei de Educação 
CAZELLA, A.A. \& BERRIET-SOLLIEC, M. O papel das cooperativas ...

Popular - de se afiliar ao Sistema Cresol, ela acompanha as principais iniciativas dirigidas por essa $\mathrm{ONG}$ na região.

O sistema Cresol, como pôde ser observado em São Joaquim, tem maiores vínculos com redes sindicais e atores políticos de esquerda. A sua ligação histórica com o Vianei pode explicar esse tipo de vínculo e a orientação dos projetos de financiamentos para a prática de uma agricultura menos produtivista e mais respeitosa do meio ambiente. No entanto, essa orientação nem sempre se traduz por ações concretas em favor do desenvolvimento territorial. As lutas sindicais entre as diferentes correntes políticas existentes no interior do sistema Cresol podem implicar na baixa adesão de agricultores familiares, que optam em seguir suas orientações técnicas e políticas. A cooperativa de São Joaquim, por exemplo, representa uma força de oposição à administração municipal, e isso gera algumas dificuldades que reduzem a sua maior inserção na zona. Além disso, ela é a única cooperativa na região que pertence ao sistema Cresol, enquanto o Sistema Sicoob encontra-se difundido na maioria dos municípios. Esta situação conduz a um certo isolamento sócio-político que gera dificuldades de funcionamento.

\section{Os processos de reinvestimento das finanças das cooperativas na economia local}

Se pegarmos o exemplo da Credicarú para o ano civil de 2006, percebe-se que a cooperativa aplicou nesse ano $\mathrm{R} \$ 10,3$ milhões em operações variadas de créditos: $\mathrm{R}$ \$ 5,6 milhões de crédito não-agrícola com recursos próprios e $\mathrm{R} \$ 4,7$ milhões de crédito agrícola com recursos repassados, sobretudo, pelo Banco do Brasil e Bancoob. No que diz respeito ao crédito agrícola, cerca

${ }^{7}$ Essa ONG tem sua sede no principal município da região serrana (Lages) e foi criada nos anos 1980 por iniciativas de agentes da Igreja Católica ligados à Pastoral da Terra e de educadores adeptos da Teologia da Libertação. Desde o começo das atividades trabalham com a difusão da agricultura agroecológica. 
CAZELLA, A.A. \& BERRIET-SOLLIEC, M. O papel das cooperativas ...

de R\$ 4 milhões são do quadro do Pronaf. As modalidades C e D desse programa correspondem, respectivamente, a $38 \%$ e $33 \%$ do total das operações de crédito agrícola.

Observa-se também a importância do montante de recursos próprios aplicados nas operações de crédito não-agrícolas. Trata-se de operações de financiamento que os associados tomam para satisfazer necessidades diversas. Do valor total captado, a cooperativa é obrigada a deixar 30\% investidos no Bancoop para constituir um fundo de abastecimento do banco. O restante pode ser reinvestido na economia local. Além disso, é essencial notar que os recursos do Pronaf, além de ajudar o agricultor individualmente, contribuem para aumentar o dinamismo da economia local. A maioria dos tomadores de crédito efetua as compras de bens e insumos no comércio do município ou da microrregião.

\section{Conclusão}

Nossa hipótese sobre a melhor eficácia da cooperativa do sistema Cresol adepta do preceito da economia solidária não pôde ser confirmada e precisa ser melhor analisada. Ainda que a Credicarú represente uma exceção no interior do Sistema Sicoob, com a adoção de estratégias de inserção de um maior número de pequenos agricultores, podemos afirmar que, independentemente do tipo de organização, a presença de uma cooperativa de crédito nas comunidades rurais aumenta de maneira significativa a captação dos recursos financeiros externos e, também, a constituição de uma poupança local.

Note-se, igualmente, que a perspectiva de abertura das cooperativas de crédito a outros atores que não somente os agricultores, embora represente uma condição para um processo de desenvolvimento territorial em zonas rurais, ainda enfrenta resistências internas, sobretudo, no interior do sistema Cresol. Todas as cooperativas podem rever o seu estatuto de cooperativa de crédito rural para se tornar cooperativas de livre admissão, já 
CAZELLA, A.A. \& BERRIET-SOLLIEC, M. O papel das cooperativas ...

que uma lei recente permite esse tipo de conversão. Isso possibilita a adesão de não-agricultores às estruturas pré-existentes que, até então, se especializaram no crédito agrícola. Para os pequenos municípios rurais, a exemplo dos dois casos deste estudo, essa mudança representa uma oportunidade para pequenos empreendedores e assalariados (incluídos os agrícolas) que têm dificuldades para acessar os serviços dos bancos. Sobre esse tema, o Sicoob vê a possibilidade de aumentar o número de associados e, por conseguinte, os lucros do sistema. Por oposição, as cooperativas do sistema Cresol temem que a integração de profissionais de outros setores, como os do comércio, provoque uma perda do controle pelos agricultores da gestão das cooperativas. Tudo indica, contudo, que esse risco seja uma condição necessária para um desenvolvimento territorializado e eficaz das cooperativas de crédito localizadas em zonas rurais.

\section{Referências bibliográficas}

ASSANKPON, U. Contribution des coopératives de crédit au développement territorial dans le sud du Brésil: Région du Plateau de Santa Catarina. Dijon, Mémoire de fin d'étude, ENESAD, 2007.

BERRIET-SOLLIEC, M., TROUVE, A.; DEPRES, C. La territorialisation de la politique agricole en France. Vers un renouvellement de l'intervention publique en agriculture ? In: LAURENT, C et DU TERTRE, C. (Coord). Régulation, secteur et territoire (à paraitre).

BURIGO, F.L. Finanças e solidariedade: uma análise do cooperativismo de crédito rural solidário no Brasil. Florianópolis, CFH/UFSC, 2006 (Tese de doutorado). 
CAZELLA, A.A. \& BERRIET-SOLLIEC, M. O papel das cooperativas ...

BÚRIGO, F.L. Cooperativa de crédito rural: agente de desenvolvimento local ou banco comercial de pequeno porte? Chapecó: Argos, 2007.

BITTENCOURT, G.A.; MAGALHÃES, R.; ABRAMOVAY, R. Informação de crédito: um meio para ampliar o acesso dos mais pobres ao sistema financeiro. Pesquisa \& Debates, São Paulo, v. $16, \mathrm{n}^{\circ} 2$ (28), 2005, pp.203-248.

CAZELLA, A. A. Cooperativismo de crédito rural: lições de uma experiência. In: MONTOYA, M. A. (Org.). Aspectos regionais do crédito rural: governo, cooperativas e informalidade. Passo Fundo, Ed. UPF, 2002, pp. 25-46, 131 p.

CAZELLA, A.A. Interfaces e (des)articulações entre políticas e atores de desenvolvimento rural; a cooperativa de crédito rural de São José do Cerrito (SC). Rio de Janeiro, FAO/ONU CPDA/UFRRJ/REDES, 2005 (Relatório de pesquisa).

CAZELLA, A.A. Contribuições metodológicas da sócioantropologia para o desenvolvimento territorial sustentável. Florianópolis, Revista Eisforia, 2006, pp. 225-248.

CAZELLA, A.A. Développement territorial et inclusion sociale: enjeux dans les zones rurales au Brésil. Grenoble, Communication au Colloque de l'ASRLF, 2007.

DELGADO, G. da C. Capital financeiro e agricultura no Brasil: 1965-1985. São Paulo/Campinas: Unicamp/Ícone, 1985.

DOUILLET A. C. Les élus ruraux face à la territorialisation de l'action publique. Revue Française de science politique, vol.53, N4, 2003, pp. 583-606. 
CAZELLA, A.A. \& BERRIET-SOLLIEC, M. O papel das cooperativas ...

DURAN, P. ET J.-C. THOENIG. L'Etat et la gestion publique territoriale. Revue Française de Science Politique, vol.46 ( $\left.\mathrm{n}^{\circ} 4\right)$, 1996, pp. 580-623.

GLOUKOVIEZOFF, G. De la bancarisation de masse à l'exclusion bancaire puis sociale. Paris, Revue française des affaires sociales, n³, 2004, pp. 11-38.

MATTEI, L.F. Impactos do Pronaf: análise e indicadores. Brasília, MDA/NEAD, 2005.

PINHEIRO, M.A.H. Cooperativas de crédito e microcrédito, história da evolução normativa no Brasil. Brasília, Banco do Brasil, $3^{\mathrm{a}}$ ed, 2005.

SAYAD, J. Crédito rural no Brasil. Avaliação das críticas e das propostas de reformas. São Paulo, FIPE/Pioneira,1984.

TROUVE, A. Régionalisation des politiques agricoles en Europe. Dijon, Université de Bourgogne, 2007 (Thèse de doctorat).

TROUVE, A.; BERRIET-SOLLIEC, M.; DEPRES, C. Charting and Theorizing the Territorialization of Agricultural Policy. Journal of Rural Studies, Vol 23, 2007.

Recebido em abril de 2009

Aceito em abril de 2010 